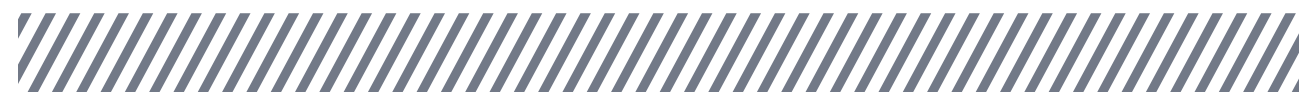

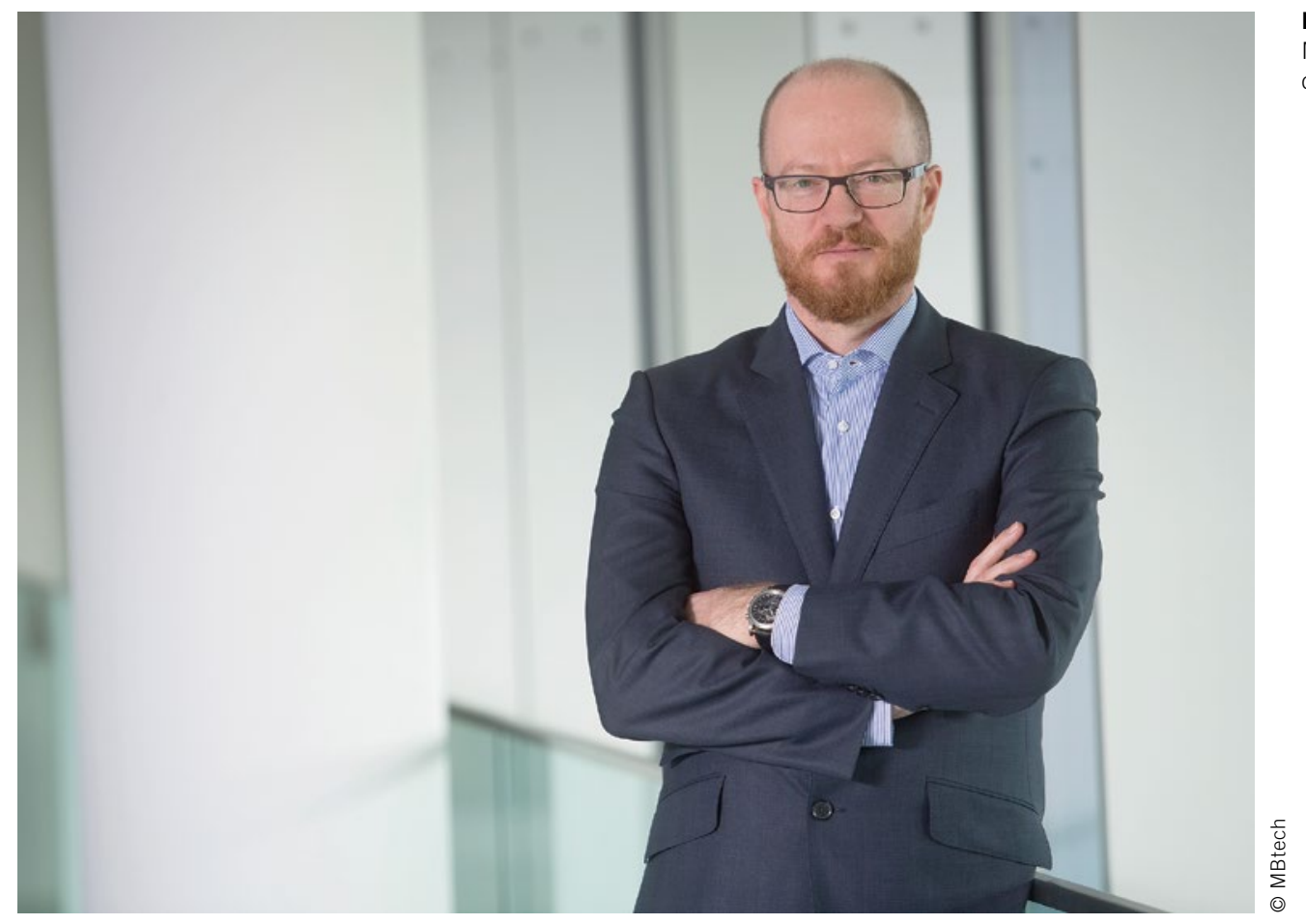

Dr. Wolfram Motz

Managing Director

der MBtech Group

\section{Innovation der Dienstleistung}

Kommentare, Artikel und Studien zur Dynamik der aktuellen und kommenden Veränderungen in der Automobilbranche sind mittlerweile Legion. Unbestritten ist, dass die fortschreitende Digitalisierung, die zunehmende Verbreitung von E- und Hybridantrieben sowie die weitere Entwicklung des (teil-) autonomen Fahrens sowohl das Produkt Automobil und seinen Lebenszyklus als auch die dahinterstehenden Geschäftsmodelle und Prozesse massiv verändert. Unbestritten auch, dass Dynamik, Umfang und Einfluss dieser Veränderungen in ihren Auswirkungen aktuell schwer abschätzbar sind. Dass gleichzeitig auch noch völlig neue Player auf die Bühne treten, verschärft diese Entwicklung zusätzlich.

Antworten und Lösungsansätze sind vielfältig. Um Geschwindigkeit im technologischen Wandel aufzunehmen, werden unter anderem Start-up-Initiativen genutzt und eigene, neue Innovationseinheiten geschaffen. Organisationen werden auf Agilität hin ausgerichtet. Die Wertschöpfung wird weiter optimiert und internationalisiert, um Kostenvorteile und Ressourcenzugänge zu begehrten Qualifikationen zu nutzen.

In den Hintergrund - zumindest der öffentlichen Diskussion - gerät dabei häufig die Frage, wie denn klassische Themen parallel bearbeitet werden können, zum Beispiel konventionelle Antriebe, die Entwicklung immer neuer Karosserievarianten oder auch die Validierung von Systemen und Fahrzeugen. Denn für OEMs und Systemlieferanten bedeutet der gleichzeitige Umgang mit diesen Herausforderungen eine enorme Anstrengung, die vielfältige Lösungsmöglichkeiten erfordert.

Kompetente Entwicklungsdienstleister (EDL) spielen hierbei eine entscheidende Rolle mit hohem Mehrwert für OEMs und Systemlieferanten. Genau im skizzierten Spannungsfeld zwischen Unterstützung in der Digitalisierung und weiterhin bei der Übernahme traditioneller Aufgaben, bieten sie maßgeschneiderte Lösungen. Denn Zielsetzung eines EDL muss sein, die Kunden mit Konzepten in der Produktentwicklung und -realisierung zu unterstützen. Für einen EDL gilt es, durch seine Dienstleistungen Kunden die Flexibilität, Reaktivität und Produktivität zu verschaffen, die diese für ihren Markterfolg benötigen.

Klar ist, dass im aktuellen Kontext nur die leistungsfähigsten und innovativsten Dienstleister einen solchen Mehrwert bieten können. Dabei ist die Bandbreite enorm und reicht von punk-tueller Unterstützung über komplexe Großprojekte bis hin zum Outsourcing. Hinzu kommt die Fähigkeit, auch international eine nahtlose Unterstützung mit hoher Qualität zu bieten. Für die besten EDL heißt das, dass sie ihr Leistungsprofil und ihre Aufstellung kontinuierlich überprüfen und zu einem Partner werden müssen, der imstande ist, Bedarfe und Anforderungen schnell zu erkennen und in innovative Dienstleistungen umzusetzen. 